\title{
Assessment of Motivation in Online Learning Environments
}

\author{
Mihaela Cocea \\ National College of Ireland, Mayor Street, Dublin 1, Ireland \\ mihaela_cocea@yahoo.com
}

\begin{abstract}
This research outline refers to the assessment of motivation in online learning environments. It includes a presentation of previous approaches, most of them based on Keller's ARCS model, and argues for an approach based on Social Cognitive Learning Theory, in particular building on self-efficacy and self-regulation concepts. The research plan includes two steps: first, detect the learners in danger of dropping-out based on their interaction with the system; second, create a model of the learner's motivation (including self-efficacy, selfregulation, goal orientation, attribution and perceived task characteristics) upon which intervention can be done.
\end{abstract}

\section{Introduction}

Motivation has always been one of the most important factors for learning (Bandura, 1986), i.e., it plays a crucial role in e-learning and especially with regard to drop-out and quality of learning. In a classical interaction between a human tutor and students in the classroom, the assessment of motivation is done by tutors, who then act according to their findings. In the case of an Intelligent Tutoring System (ITS), the assessment of motivation is also needed in order to interact with students according to their level of motivation.

We propose an approach to assessment of motivation in two stages: first, indirect assessment/observation - the aim of this stage is to identify learners that are in danger of dropping out or giving up as early as possible using unobtrusive observation methods; second, explicit elicitation: in order to inform a personalized and suitable intervention, the system would explicitly explore and verify the learners' motivational level (self-efficacy, self-regulation, goal orientation, attribution, perceived characteristics of the task etc). Thus, we are addressing the following research questions: Which factors in the learning behavior can predict drop-out? How to assess/create a learner model of his/her motivation?

\section{Background}

Human tutors usually infer motivation from observational cues - like mimics, posture, gesture, conversational cues etc. which are difficult to be processed by adaptive systems (although there are efforts in this direction - i.e.: Kapoor, Picard and Ivanov, 2004; D’Mello et al., 2005; Fernandez and Picard, 2005). Thus, most of the research

V. Wade, H. Ashman, and B. Smyth (Eds.): AH 2006, LNCS 4018, pp. 414-418, 2006.

(c) Springer-Verlag Berlin Heidelberg 2006 
is directed towards finding a way to assess motivation from cues that can be easily processed automatically (e.g. learner's interactions with the system, time spent on a task, his/her statements about his/her level of motivation etc.).

Three previous works are of particular interest for our research. All of them are related to Keller's ARCS model (Keller, 1987), briefly presented here: ARCS stands for Attention, Relevance, Confidence and Satisfaction. Gaining and retaining the learner's attention is necessary for an efficient learning, relevance (of the learning content) is a condition for attention and motivation, confidence determines the level of effort invested in learning and satisfaction refers to the reward gained from the learning experience. The three mentioned works came up with interesting approaches. One of these approaches has been presented by de Vicente \& Pain (2003); they proposed several rules to infer motivational states from two sources: the interactions of the students with the tutoring system and their motivational traits. A second approach was developed by Qu, Wang \& Johnson (2005) and infers three aspects of motivation - confidence, confusion and effort from several sources: the learner's focus of attention, the current task and expected time to perform the task.; they were interested in particular in low confidence, high confusion and low effort, as these are strong indicators of the student giving up. A third approach was introduced by Zhang, Cheng, He\& Huang (2003); they also started from ARCS model and assessed two of the model's variables: attention and confidence.

All three approaches focus on motivational states and a way to measure them without asking the learner. The ambition to build a system that is able to assess motivation without specifically asking the learners about it seems too high for our current knowledge. The assessment of motivation classically includes either observation or self-report or both. The idea of getting a system to do what humans do is a goal that seems quite far - at least when we talk about emotions, feelings, motivation and will. And as these aspects are important for learning, they need to be taken into consideration.

That is why our approach for the assessment of motivation is based on Social Cognitive Learning Theory and especially related to self-efficacy (SE) and selfregulation (SR) concepts. SE is generally described by Bandura (1986) as the confidence that the individual has in his/her ability to control his/her thoughts, feelings and actions; more specifically, it refers to a person's belief/ expectancy in his/her capacity to successfully complete a task. SR refers to a person's ability to control his/her actions, in our case learning (Schunk \& Zimmerman, 1994; Zimmerman, 1994). Karoly (1993, p.25) defines SR as "those processes (...) that enable an individual to guide his/her goal-directed activities over time and across changing circumstances (contexts)".

We argue that Social Cognitive Learning Theory is a sound theoretical base for assessment of motivation. It is a well established construct in the literature. There is broad evidence that this theory has good application in classroom (Tuckman, 1999; Schraw \& Brooks, 2000), as well as in online learning (Hodges, 2004; Irizarry, 2002) and blended learning (Wang \& Newlin, 2002). The theory offers a variety of possibilities to intervene in order to motivate the learner in a personalized way. It also offers a framework for influencing the learner's subjective control of the task through motivational beliefs (SE) and cognitive learning strategies (SR/ self-monitoring). 


\section{Methodology}

In accordance with the two stages of assessment proposed above, this project is split into: the prediction of drop-outs and the dialog-based creation of learner model.

\subsection{Which Factors in the Learning Behavior Can Predict Drop-Out?}

The approach for this first research question will build upon and elaborate Johnson's approach (Qu, Wang \& Johnson, 2005): This research aims at identifying the learners with the risk of dropping out. Rather than directly inferring particular motivational states from the observed behavior, we propose to use behavioral cues as indicators that can predict the giving-up risk. These indicators related to the concept of SR include: browsing fast rather than reading, skipping sections, non-systematic progression, and answering questions quickly (in less time than the minimum required time for at least reading the questions). Another indicator is how often and how insistent the learner seeks for help from peers/instructor. Also if the learner is searching external content for a related topic it may be a sign of getting lost in the course content; it may also be a sign of an elaboration cognitive strategy.

Perhaps the most intuitive and easy to use indicator is time (time required higher than predicted time). It is interesting that de Vicente \& Pain (2003) used it to infer confidence or lack of interest, while Qu, Wang \& Johnson (2005) used it to infer effort. Time is probably a component of each of the three mentioned aspects, but is not sufficient to infer any of them. We use time as a general indicator of drop-out risk: a too short or a too long focus on an issue may indicate "problems". Of course, both could be due to other factors: a too short time spent on a task might be explained by a good knowledge and exceeding time could be justified by factors like breaks or deep thought. These situations can be clarified by asking the learner.

To evaluate the drop-out risk prediction two comparison studies will be conducted that compare the ITS' prediction against the learner's performance and continuity with the course, on one hand, and human tutors' prediction (based on the learner's interactions with the ITS), on the other hand. The benefits from the second approach are: human teachers can provide explanations for the learners' behavior; they can identify and explain contradictory situations (i.e. the learner's behavior indicates drop-out/good performance, but the actual behavior of the learner is different).

The next step after spotting the learners in danger of giving-up is interacting with them in order to identify the ones really in danger (as situations like the ones mentioned above can occur) and engage them in a dialog in order to explicitly elicit information about their motivation and build a learner model. Figure 1 illustrates the steps involved in our approach.

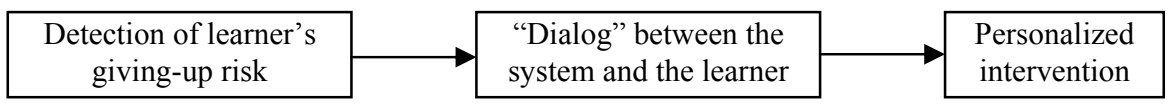

Fig. 1. The assessment process 


\subsection{How to Build a Learner Model of Motivation?}

The second research question will be approached based on a dialog with the learner. The dialog deals with the following aspects: a) Inform and explain the learner about the dialog: the learners identified to be in danger of giving up will be informed by the system that it has noticed some "confusing" behavior and informs the learner about the next questions that he/she will be asked in order to identify "the problem"; b) Ask the learners about their SE, SR, goal-orientation (GO), attribution of their performance and perceived characteristics of the task at hand.

To elicit the level of SE, SR and GO, adapted versions of existing questionnaires will be used. To elicit the attribution of their performance, learners will have to choose from the following options (depending on the level of performance): my (lack of) ability; my (lack of) effort; (bad) luck; task reasonable (hard) difficulty. Perceived characteristics of the task include difficulty, cognitive interest, sensory interest (structure/ presentation), controllability and challenge. From the attribution choice we can infer the locus of control and the control-non control dimension. This information together with the other measured aspects will be included in a learner model.

An experiment will be conducted to investigate the reliability and construct validity of the adapted SE, SR and GO questionnaires. The construct validity of the attribution measurement is assured by the fact that the options given for answering are from the theory of attribution (Heider, 1958; Weiner, 1974). A random group of students will participate in the experiment. They will be required to complete the questionnaires and the gathered data will be analyzed in three ways: reliability coefficients will be calculated; a confirmatory factor analysis (for the types of GO) and goodness-of-fit of the model will be investigated.

\section{Summary}

Social Cognitive Learning Theory offers a frame for a deep knowledge of a learner's motivation and several possibilities for intervention. It can, thus, serve as a sound theoretical basis for assessment of motivation in online learning environments. Our research includes two aspects: the predictions of the giving-up risk and the development of a learner motivational model (including SE, SR, GO, attribution and perceived task characteristics).

By the actual time, our research has covered the research questions, the literature review and partially the methodology. Future work includes: define the methodology in detail, conduct a study to predict and validate the dropping-out risk assessment and one to build and validate the learner's model of motivation; collect and analyse the data and draw conclusions about this approach.

\section{References}

1. Bandura, A.: Social foundations of thought and action: A social cognitive theory. Englewood Cliffs, NJ: Prentice Hall (1986)

2. De Vicente, A., Pain, H.: Informing the Detection of the Students' Motivational State: an empirical Study. In Cerri, S. A.; Gouarderes, G.; Paraguau, F: Intelligent Tutoring Systems, 6th International Conference. Berlin: Springer-Verlag., (2002) 933-943 
3. De Vicente, A., Pain, H.: Validating the Detection of a student's Motivational State. In Mendez Vilas, A.; Mesa Gonzalez, J. A.; Mesa Gonzalez, J. (eds): Proceedings of the Second International Conference on Multimedia Information \& Communication Technologies in Education (m-ICTE2003), number 15 of "Sociedad de la Informacion" Series, Volume III, (2003)

4. D'Mello, S. K., Craig, S. D., Gholson, B., Franklin, S., Picard, R. W., Graesser, A. C.: Integrating Affect Sensors in an Intelligent Tutoring System, In Affective Interactions: The Computer in the Affective Loop Workshop at 2005 International conference on Intelligent User Interfaces (pp. 7-13) New York: AMC Press (2005)

5. Fernandez, R., Picard, R. W.: Classical and Novel Discriminant Features for Affect Recognition from Speech, Interspeech 2005 - Eurospeech 9th European Conference on Speech Communication and Technology pp. September 4-8, Lisbon Portugal (2005)

6. Heider, F.: The Psychology of Interpersonal Relations, N.Y.: John Wiley \& Sons, (1958)

7. Hodges, C. B.: Designing to Motivate: Motivational Techniques to Incorporate in ELearning Experiences, The Journal of Interactive Online Learning, Vol. 2, No 3 (2004)

8. Irizarry R.: Self-Efficacy \& Motivation Effects on Online Psychology Student Retention. USDLA Journal, Vol. 16, No 12. (2002)

9. Karoly, P.: Mechanisms of self-regulation: a systems view. Annual Review of Psychology, Vol. 44, (1993) 23-52

10. Kapoor, A., Picard, R.W., Ivanov, Y.: Probabilistic Combination of Multiple Modalities to Detect Interest, International Conference on Pattern Recognition, Cambridge, U.K. (2004)

11. Keller, J. M.: Development and use of the ARCS model of instructional design. Journal of Instructional Development, 10(3), (1987), 2-10

12. Qu, L., Wang N., Johnson, W. L.: Detecting the Learner's Motivational States in an Interactive Learning Environment. Artificial Intelligence in Education. C.-K. Looi et al. (Eds.), IOS Press (2005) 547-554

13. Qu, L., Wang N., Johnson, W. L.: Using Learner Focus of attention to Detect Learner Motivation Factors. In Ardissono, L., Brna, P., Mitrovic, A.: User Modelling 2005. Springer-Verlag Berlin Heidelberg (2005) 70-73

14. Schraw, G., Brooks, D. W.: Helping Students Self-Regulate in Math and Sciences Courses: Improving the Will and the Skill (2000) http://dwb.unl.edu/Chau/SR/Self_Reg.html

15. Schunk, D. H., \& Zimmerman, B. J.. Self-regulation of learning and performance: Issues and educational applications. Hillsdale, NJ: Lawrence Erlbaum (1994)

16. Tuckman, W. B.: A Tripartite Model of Motivation for Achievement: Attitude/Drive/ Strategy (1999) http://dwb.unl.edu/Chau/CompMod.html

17. Wang, A. Y., Newlin, M. H.: Predictors of web-student performance: The role of selfefficacy and reasons for taking an on-line class. Computers in Human Behavior, 18 (2002)151-163

18. Weiner, B.: Achievement motivation and attribution theory. Morristown, N.Y.: General learning Press (1974)

19. Zhang, G., Cheng, Z., He, A., Huang, T. A WWW-based Learner's Learning Motivation Detecting System. Proceedings of International Workshop on "Research Directions and Challenge Problems in Advanced Information Systems Engineering", Honjo City, Japan, September 16 - 19, 2003, http://www.akita-pu.ac.jp/system/KEST2003/

20. Zimmerman, B. J.: Dimensions of academic self-regulation: A conceptual framework for education. In Schunk, D. H., Zimmerman, B. J. (eds.):Self-regulation of learning and performance: Issues and educational applications. Hillsdale, NJ: Erlbaum (1994) 3-22. 